\title{
Bioprosthetic valve fracture: Technical insights from a multicenter study
}

Keith B. Allen, MD, ${ }^{\mathrm{a}}$ Adnan K. Chhatriwalla, MD, ${ }^{\mathrm{b}}$ John T. Saxon, MD, ${ }^{\mathrm{b}}$ David J. Cohen, MD, MSc, ${ }^{\mathrm{b}}$

Tom C. Nguyen, ${ }^{\mathrm{c}}$ John Webb, MD, ${ }^{\mathrm{d}}$ Pranav Loyalka, MD, ${ }^{\mathrm{d}}$ Anthony A. Bavry, MD, MPH,

Joshua D. Rovin, MD, ${ }^{\mathrm{f}}$ Brian Whisenant, MD, ${ }^{\mathrm{g}}$ Danny Dvir, MD, ${ }^{\mathrm{d}}$ Kevin F. Kennedy, MS, ${ }^{\mathrm{b}}$

Vinod Thourani, MD, ${ }^{\mathrm{h}}$ and Richard Lee, MD, MBA, ${ }^{\mathrm{i}}$ on behalf of the Bioprosthetic Valve Fracture

Investigators

\section{ABSTRACT}

Objective: Valve-in-valve transcatheter aortic valve replacement (VIV TAVR) can result in high residual gradients that are associated with increased mortality. Bioprosthetic valve fracture (BVF) has been shown to improve residual gradients following VIV TAVR; however, factors influencing the results of BVF have not been studied.

Methods: BVF was performed in 75 patients at 21 centers. Hierarchical multiple linear regression was performed to identify variables that were associated with lower final transvalvular gradient.

Results: Surgical valves with a median true internal diameter of $18.5 \mathrm{~mm}$ (interquartile range, 17.0-20.5 mm) were treated with VIV TAVR in conjunction with BVF using balloon-expandable $(n=43)$ or self-expanding $(n=32)$ transcatheter heart valves with a median size of $23 \mathrm{~mm}$ (interquartile range, 23-23 mm). There were no aortic root disruptions, coronary occlusions, or new pacemakers; in-hospital or 30-day mortality was $2.6 \%$ ( 2 out of 75 ). Final mean transvalvular gradient was $9.2 \pm 6.3 \mathrm{~mm} \mathrm{Hg}$, but was significantly lower when BVF was performed after VIV TAVR compared with BVF first $(8.1 \pm 4.8 \mathrm{~mm} \mathrm{Hg}$ vs $16.9 \pm 10.1 \mathrm{~mm} \mathrm{Hg} ; P<.001)$. After adjusting for timing of BVF (ie, before or after VIV TAVR), transcatheter heart valve size/type, surgical valve mode of failure, true internal diameter, and baseline gradient and BVF balloon size, performing BVF after VIV TAVR $(P<.001)$ and using a larger BVF balloon $(P=.038)$ were the only independent predictors of lower final mean gradient.

Conclusions: BVF can be performed safely and results in reduced residual transvalvular gradients. Performing BVF after VIV TAVR and using larger balloon appears to achieve the best hemodynamic results. (J Thorac Cardiovasc Surg 2019;158:1317-28)

Computed tomography image demonstrating bio-
prosthetic valve fracture (red circle).
Central Message
Bioprosthetic valve fracture (BVF) reduces
residual gradients and increases valve effective
orifice area; balloon size and performing BVF
after VIV TAVR were predictive of best
hemodynamic results.
Perspective
Valve in valve (VIV) TAVR can result in
patient-prosthesis-mismatch and high residual
gradients that are associated with increased
1-year mortality. Bioprosthetic valve fracture
(BVF) can be performed safely and results in
reduced residual gradients and increased valve
effective orifice area. Performing BVF after
VIV TAVR and using a larger balloon achieves
the best hemodynamic results.
(a)

See Commentaries on pages 1329 and 1331.

\footnotetext{
From the Departments of ${ }^{\mathrm{a} C}$ Cardiothoracic Surgery and ${ }^{\mathrm{b}}$ Cardiology, Saint Luke's Mid America Heart Institute and University of Missouri-Kansas City School of Medicine, Kansas City, Mo; ${ }^{\mathrm{c} D e p a r t m e n t}$ of Cardiology, University of Texas Medical School at Houston, Houston, Tex; ${ }^{\mathrm{d}}$ Department of Cardiology, University of British Columbia, Vancouver, British Columbia, Canada; ${ }^{\mathrm{e}}$ Department of Cardiology, University of Florida, Gainesville, Fla; ${ }^{\mathrm{f}}$ Department of Cardiothoracic Surgery, Morton Plant Hospital, Tampa Bay, Fla; ${ }^{\mathrm{g}}$ Department of Cardiology, Intermountain Heart Institute, Murry, Utah; ${ }^{\mathrm{h}}$ Department of Cardiothoracic Surgery, MedStar Heart and Vascular Institute/Georgetown University School of Medicine, Washington, DC; and ${ }^{\mathrm{i}}$ Department of Cardiothoracic Surgery, Saint Louis University School of Medicine, Saint Louis, Mo.
}

Additional collaborators not listed as authors above who encompass the Bioprosthetic Valve Fracture Investigators are listed in the Acknowledgements.

Read at the 44th Annual Meeting of The Western Thoracic Surgical Association, Goleta, California, June 27-30, 2018.

Received for publication June 22, 2018; revisions received Jan 9, 2019; accepted for publication Jan 21, 2019; available ahead of print March 8, 2019.

Address for reprints: Keith B. Allen, MD, Saint Luke's Mid America Heart Institute and University of Missouri-Kansas City School of Medicine, 4320 Wornall Rd, Medical Plaza II, Ste 50, Kansas City, MO 64111 (E-mail: kallen2340@aol.com). 0022-5223/ $\$ 36.00$

Copyright (C) 2019 by The American Association for Thoracic Surgery https://doi.org/10.1016/j.jtcvs.2019.01.073 


\section{Abbreviations and Acronyms}

$\mathrm{BVF}=$ bioprosthetic valve fracture

EOA $=$ effective orifice area

ID $=$ internal diameter

PPM = prosthesis-patient-mismatch

THV $=$ transcatheter heart valve

VIV TAVR = valve-in-valve transcatheter aortic valve replacement

Valve-in-valve transcatheter aortic valve replacement (VIV TAVR) using either the balloon-expandable Sapien (Edwards Lifesciences, Irvine, Calif) or self-expanding CoreValve (Medtronic, Minneapolis, Minn) transcatheter heart valve (THV) is an approved treatment option for patients with failed surgical bioprosthetic valves who are at prohibitive or high surgical reoperative risk. ${ }^{1-5}$ There are, however, significant concerns with VIV TAVR. In particular, previous studies have demonstrated that VIV TAVR in patients with small surgical bioprostheses or with pre-existing prosthesis-patient mismatch (PPM) can result in high residual transvalvular gradients and reduced 1-year survival. . $^{-10}$

Bioprosthetic valve fracture (BVF) is a technique that utilizes a noncompliant balloon and high-pressure inflation to fracture the surgical valve and allow further expansion of the THV (Figure 1), and has been shown to reduce residual gradients following VIV TAVR. ${ }^{11-18}$ In this study, we used data from a multicenter study to explore factors influencing the final procedural hemodynamics following VIV TAVR with BVF.

\section{METHODS}

We analyzed results from patients undergoing VIV TAVR with BVF from 21 centers. Efforts were made to ensure collection of consecutive BVF procedures from each center. All patients provided informed consent for the procedure. Procedure-related and demographic data were

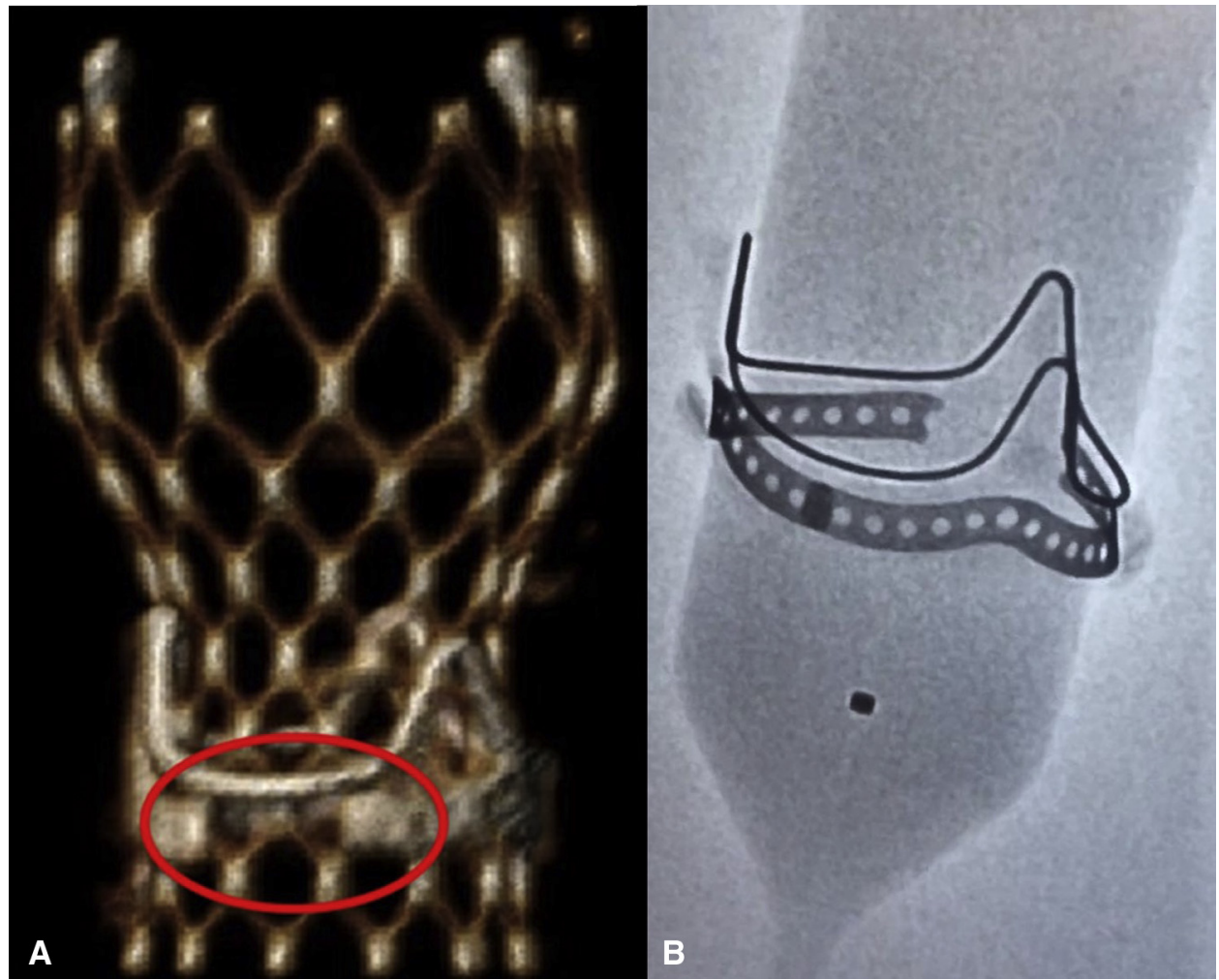

FIGURE 1. A, Postoperative computed tomography image demonstrating the single fracture point (red circle) in a 21 mm Edwards Magna tissue valve (Edwards Lifesciences, Irvine, Calif) in a patient who underwent valve-in-valve transcatheter aortic valve replacement (VIV TAVR) using a 23 mm Evolut R (Medtronic, Minneapolis, Minn) followed by bioprosthetic valve fracture (BVF) using a $22 \mathrm{~mm}$ True Dilation Balloon (CR Bard, Murray Hill, NJ) and high-pressure inflation. B, Fluoroscopic image obtained during previous bench testing ${ }^{11}$ of a $21 \mathrm{~mm}$ Edwards Magna tissue valve fractured using a $22 \mathrm{~mm}$ True Dilation balloon (CR Bard) has similarities. 


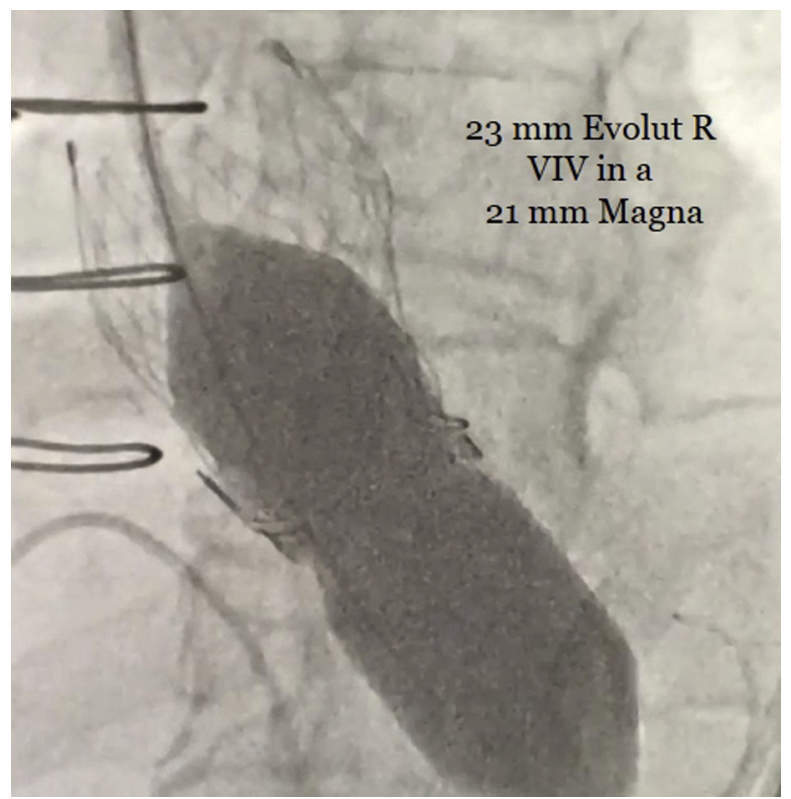

VIDEO 1. Bioprosthetic valve fracture (BVF) being performed with a 22 True Dilation balloon (C.R. Bard, Murray Hill, NJ) to reduce the high residual gradient following valve-in-valve transcatheter aortic valve replacement with a $23 \mathrm{~mm}$ Evolut R (Medtronic, Minneapolis, Minn) in a $21 \mathrm{~mm}$ Edwards Magna (Edwards Lifesciences, Irvine, Calif) surgical tissue valve. Video available at: https://www.jtcvs.org/article/S00225223(19)30287-9/fulltext.

de-identified and provided to Saint Luke's Mid America Heart Institute where they were analyzed. The Institutional Review Board at Saint Luke's Mid America Heart Institute authorized this study and granted a waiver of informed consent.

Surgical valves were categorized according to their true internal diameter (ID) as small ( $\leq 18.5 \mathrm{~mm}$ ), intermediate ( $>18.5$ to $\leq 21 \mathrm{~mm}$ ), or large $(>21 \mathrm{~mm}) .{ }^{19}$ The timing of BVF (ie, before or after VIV TAVR), THV selection, and postprocedure anticoagulation regimens were at the discretion of those performing the operations. The balloon size selected to perform BVF was at the discretion of those performing the operations; however, prior publications have suggested that a balloon $1 \mathrm{~mm}$ larger than the labeled surgical valve size is effective at fracturing the valve. ${ }^{11,12}$ The noncompliant balloons used to perform BVF were categorized as small if they were $<3 \mathrm{~mm}$ larger than the true ID of the surgical valve being fractured and large if they were $\geq 3 \mathrm{~mm}$ larger than the surgical valve true ID. THVs were categorized as being either right sized or up sized based on whether the heart team selected a THV size equal to or larger than that recommended by Valve in Valve App version 2.0 (UBQO Limited, London, United Kingdom) for the patient's surgical valve. ${ }^{19}$

The technique for BVF has been described previously. ${ }^{11-13}$ Successful fracture of the surgical valve with a high-pressure balloon inflation performed during rapid ventricular pacing is noted when the waist of the balloon releases (Video 1) and/or there is a sudden drop in inflation pressure on the indeflator. Invasive hemodynamic measurements and calculation of the valve effective orifice area (EOA) were performed at baseline, immediately after VIV TAVR, and after BVF; when BVF was performed first, only baseline and final hemodynamic measurements were obtained.

\section{Statistical Analysis}

Continuous variables are expressed as mean \pm standard deviation when normally distributed or median values with interquartile ranges (IQR).
TABLE 1. Characteristics of patients undergoing bioprosthetic valve fracture $(\mathbf{N}=\mathbf{7 5})$

\begin{tabular}{lc}
\hline \multicolumn{1}{c}{ Characteristic } & Result \\
\hline Age (y) & $74.4 \pm 10.9$ \\
STS PROM & $6.5 \% \pm 5.2$ \\
\hline Age of surgical prosthesis (y) & $10.3 \pm 5.1$ \\
Mean labeled surgical valve size (mm) & $21 \pm 2.1(19-25)$ \\
\hline Surgical valve mean true ID (mm) & $18.3 \pm 1.8(15.5-23)$ \\
Surgical valve category* & \\
Small & $52.0(39)$ \\
Intermediate & $45.3(34)$ \\
Large & $2.7(2)$ \\
Surgical valve mode of failure & \\
Stenosis & $73.3(55)$ \\
Regurgitation & $17.3(13)$ \\
Mixed & $9.3(7)$ \\
Transcatheter valve type & \\
Balloon expandable & $57.3(43)$ \\
Sapien S3 $\dagger$ & $50.7(38)$ \\
Sapien XT $\dagger$ & $6.7(5)$ \\
Self-expanding & $42.7(32)$ \\
Evolut R $\ddagger$ & $42.7(32)$ \\
TAVR access & \\
Transfemoral & $90.7(68)$ \\
Transcarotid & $6.7(5)$ \\
Transcaval & $1.3(1)$ \\
Subclavian & $1.3(1)$ \\
\hline Vas & \\
\hline
\end{tabular}

Values are presented as mean \pm standard deviation, mean \pm standard deviation (interquartile range), or \% (n). STS PROM, Society of Thoracic Surgeons Predicted Risk of Mortality score; $I D$, internal diameter; $T A V R$, transcatheter aortic valve replacement. *Small: true ID $\leq 18.5 \mathrm{~mm}$, Intermediate: true ID $>18.5$ to $\leq 21 \mathrm{~mm}$, and Large: true ID $>21 \mathrm{~mm}$. $\dagger$ Edwards Lifesciences, Irvine, Calif. $\ddagger$ Medtronic, Minneapolis, Minn.

Categorical variables are expressed as percentages or frequencies. Continuous variables were compared using Student $t$ test. Categorical variables were compared using $\chi^{2}$ test. Final mean gradient was our primary outcome variable and was treated as a continuous variable. After using the Shapiro-Wilk test to test normality $(P=.4)$, we used a hierarchical multiple linear regression with forced entry of variables chosen a priori. The candidate variables used in the model were: timing of BVF (ie, before or after VIV TAVR), type of THV (ie, self-expanding vs balloonexpandable), right-sized versus up-sized THV, surgical valve true ID (ie, small, intermediate, or large), baseline mean gradient, mode of valve failure (ie, stenosis, insufficiency, or mixed), and BVF balloon size (ie, large vs small), and THV size (ie, $20 \mathrm{~mm}, 23 \mathrm{~mm}$, or $26 \mathrm{~mm}$ ). Analyses were performed using SAS version 9.4 (SAS Institute Inc, Cary, NC).

\section{RESULTS}

A total of 75 patients underwent VIV TAVR with BVF at 21 centers between March 2016 and April 2018. Table 1 summarizes the general characteristics of patients undergoing BVF. VIV TAVR and BVF were performed via transfemoral access in $90.7 \%$ (68 out of 75 ) using both self-expanding $(\mathrm{n}=33)$ and balloon-expandable $(\mathrm{n}=42)$ THVs. Median diameter of the implanted THV was similar for the balloon expandable and self- 
expanding valves $(23 \mathrm{~mm}$ [IQR, 23-23 mm] vs $23 \mathrm{~mm}$ [IQR, 23-26 mm]; $P=.2$ ). The selected THV was considered up sized in $53 \%$ of patients ( 40 out of 75 ). The distribution of treated surgical valves by brand and labeled valve size along with the types and sizes of THVs implanted are provided in Table E1. BVF was performed after VIV TAVR in $88 \%$ of patients ( 66 out of 75 ), whereas $12 \%$ of patients ( 9 out of 75 ) underwent BVF first followed by VIV TAVR. BVF was performed using True Dilation $(n=69)$, Atlas Gold $(n=4)$, or VIDA $(n=2)$ balloons (C.R. Bard, Inc, Murray Hill, NJ) that were most frequently $1 \mathrm{~mm}$ larger (60 out of 75) than the labeled surgical valve size. Small balloons $(<3 \mathrm{~mm}$ larger than the surgical valve true ID being fractured) were used to perform BVF in $16.0 \%$ of patients (12 out of 75 ) and the frequency was similar among patients who had BVF performed after TAVR compared with patients who underwent BVF first $(15.2 \%$ [10 out of 66 ] vs $22.2 \%$ [2 out of 9]; $P=.587$ ). Valve fracture threshold ranged from 8 to 27 atmospheres depending on brand/model of surgical valve being fractured.

BVF was performed successfully in $100 \%$ of patients (75 out of 75). In hospital and/or 30-day mortality was $2.7 \%$ ( 2 out of 75 ) with an observed/expected Society of Thoracic Surgeons Predicted Risk of Mortality ratio of 0.4 . No patients experienced annular/aortic root rupture, coronary occlusion, or required a new pacemaker. Final postprocedure aortic insufficiency was none $(\mathrm{n}=71)$ or trivial $(\mathrm{n}=4)$. In 3 patients considered to have mild/ moderate paravalvular leak before the procedure,

TABLE 2. Patient demographic characteristics and hemodynamic results categorized by timing of bioprosthetic valve fracture (BVF)

\begin{tabular}{|c|c|c|c|c|}
\hline \multirow[b]{2}{*}{ Characteristic } & \multirow[b]{2}{*}{$\begin{array}{c}\text { Total } \\
(\mathbf{N}=\mathbf{7 5})\end{array}$} & \multicolumn{2}{|c|}{ BVF timing } & \multirow[b]{2}{*}{$P$ value } \\
\hline & & $\begin{array}{c}\text { BVF first } \\
(n=9)\end{array}$ & $\begin{array}{c}\text { TAVR first } \\
(\mathrm{n}=66)\end{array}$ & \\
\hline Patient age (y) & $74.4 \pm 10.9$ & $78.7 \pm 5.2$ & $73.8 \pm 11.3$ & .213 \\
\hline STS PROM & $6.5 \pm 5.2$ & $7.6 \pm 5.1$ & $6.4 \pm 5.2$ & .534 \\
\hline Baseline ejection fraction $(\%)$ & $56.8 \pm 9.4$ & $58.0 \pm 9.4$ & $56.8 \pm 9.5$ & .897 \\
\hline Labeled surgical valve size (mm) & $21.5 \pm 2.0$ & $20.8 \pm 2.1$ & $21.5 \pm 1.9$ & .273 \\
\hline True surgical ID (mm) & $18.5 \pm 2.0$ & $17.7 \pm 2.1$ & $18.7 \pm 2.0$ & .190 \\
\hline $\begin{array}{l}\text { Surgical valve failure mode } \\
\text { Insufficiency } \\
\text { Stenosis } \\
\text { Mixed }\end{array}$ & $\begin{array}{c}13(17.3) \\
55(73.3) \\
7(9.3)\end{array}$ & $\begin{array}{l}1(11.1) \\
8(88.9) \\
0(0.0)\end{array}$ & $\begin{array}{r}12(18.2) \\
47(71.2) \\
7(10.6)\end{array}$ & .467 \\
\hline $\begin{array}{l}\text { TAVR access } \\
\text { Transcaval } \\
\text { Transfemoral } \\
\text { Carotid } \\
\text { Subclavian }\end{array}$ & $\begin{aligned} 1 & (1.3) \\
68 & (90.7) \\
5 & (6.7) \\
1 & (1.3)\end{aligned}$ & $\begin{array}{l}0(0.0) \\
9(100.0) \\
0(0.0) \\
0(0.0)\end{array}$ & $\begin{array}{c}1(1.5) \\
59(89.4) \\
5(7.6) \\
1(1.5)\end{array}$ & .788 \\
\hline $\begin{array}{l}\text { THV type } \\
\text { Self-expanding } \\
\text { Balloon-expandable }\end{array}$ & $\begin{array}{l}32(42.7) \\
43(53.3)\end{array}$ & $\begin{array}{l}3(33.3) \\
6(66.7)\end{array}$ & $\begin{array}{l}29(43.9) \\
37(56.1)\end{array}$ & .755 \\
\hline THV size (mm) & $23.1 \pm 1.9$ & $22.3 \pm 2.0$ & $23.2 \pm 1.8$ & .181 \\
\hline $\begin{array}{l}\text { THV sizing strategy } \\
\text { Right sized } \\
\text { Up sized }\end{array}$ & $\begin{array}{l}35(46.7) \\
40(53.3)\end{array}$ & $\begin{array}{l}2(22.2) \\
7(77.8)\end{array}$ & $\begin{array}{l}33(50.0) \\
33(50.0)\end{array}$ & .117 \\
\hline BVF balloon diameter minus surgical valve true ID $<3 \mathrm{~mm}$ & $12(16.0)$ & $2(22.2)$ & $10(15.2)$ & .587 \\
\hline BVF threshold (ATM) & $15.8 \pm 4.2$ & $14.6 \pm 3.1$ & $16.0 \pm 4.3$ & \\
\hline Baseline gradient $(\mathrm{mm} \mathrm{Hg})$ & $40.3 \pm 15.8$ & $37.9 \pm 16.5$ & $40.6 \pm 15.8$ & .633 \\
\hline Post-TAVR mean gradient (mm Hg) & $19.0 \pm 8.8$ & NA & $19.0 \pm 8.8$ & \\
\hline Post-BVF final mean gradient (mm Hg) & $9.2 \pm 6.3$ & $16.9 \pm 10.1$ & $8.1 \pm 4.8$ & $<.001$ \\
\hline Baseline valve EOA $\left(\mathrm{cm}^{2}\right)$ & $0.8 \pm 0.3$ & $0.8 \pm 0.3$ & $0.8 \pm 0.3$ & .748 \\
\hline Post-TAVR valve EOA $\left(\mathrm{cm}^{2}\right)$ & $1.4 \pm 0.7$ & NA & $1.4 \pm 0.8$ & \\
\hline Post-BVF final valve EOA $\left(\mathrm{cm}^{2}\right)$ & $2.1 \pm 0.8$ & $1.9 \pm 0.2$ & $2.1 \pm 0.8$ & 610 \\
\hline
\end{tabular}

Continuous variables were compared using Student $t$ test and categorical variables were compared using $\chi^{2}$ test. Values are presented as $\mathrm{n}(\%)$ or mean \pm standard deviation. $B V F$, Bioprosthetic valve fracture; TAVR, transcatheter aortic valve replacement; STS PROM, Society of Thoracic Surgeons Predicted Risk of Mortality score; ID, internal diameter; $T H V$, transcatheter heart valve; $A T M$, atmosphere; $N A$, not applicable; $E O A$, effective orifice area. 
TABLE 3. Univariable and multivariable predictors of final mean gradient following bioprosthetic valve fracture $(B V F)(N=75)$

\begin{tabular}{|c|c|c|c|c|}
\hline \multirow[b]{2}{*}{ Variable } & \multicolumn{2}{|c|}{ Univariate association } & \multicolumn{2}{|c|}{ Multivariable association } \\
\hline & $\begin{array}{c}\text { Beta weight } * \\
(95 \% \text { confidence interval })\end{array}$ & $P$ value & $\begin{array}{c}\text { Beta weight } * \\
(95 \% \text { confidence interval })\end{array}$ & $P$ value \\
\hline BVF after VIV TAVR vs BVF first & 8.81 (4.76 to 12.86$)$ & $<.001$ & $8.6 .4(3.87$ to 13.41$)$ & $<.0001$ \\
\hline Self-expandable THV type & $0.09(-2.97$ to 3.15$)$ & .95 & $0.99(-2.85$ to 4.82$)$ & .61 \\
\hline THV right sized vs up sized & $-0.77(-3.75$ to 2.21$)$ & .61 & $0.38(-4.05$ to 4.81$)$ & .86 \\
\hline \multicolumn{5}{|l|}{ Surgical valve true ID } \\
\hline Small vs large & $3.23(-3.40$ to 10.86$)$ & .40 & $4.27(-6.74$ to 15.27$)$ & .43 \\
\hline Intermediate vs large & $3.48(-4.21$ to 11.18$)$ & .37 & $4.16(-5.63$ to 13.95$)$ & .40 \\
\hline Baseline mean gradient (mm Hg) & $0.06(-0.04$ to 0.15$)$ & .24 & $0.10(-0.010$ to 0.209$)$ & .075 \\
\hline \multicolumn{5}{|l|}{ Mode of valve failure } \\
\hline Insufficiency vs mixed & $-2.35(-8.28$ to 3.58$)$ & .43 & -0.22 ( -6.40 to 5.96$)$ & .94 \\
\hline Stenosis vs mixed & $0.27(-4.82$ to 5.35$)$ & .92 & $-0.86(-6.09$ to 4.36$)$ & .74 \\
\hline $\mathrm{BVF}$ balloon size minus surgical valve true $\mathrm{ID} \geq 3 \mathrm{~mm}$ vs $<3 \mathrm{~mm}$ & $4.62(0.57$ to 8.66$)$ & .026 & $4.76(10.27$ to 9.24$)$ & .038 \\
\hline \multicolumn{5}{|l|}{ THV size } \\
\hline $20 \mathrm{~mm}$ vs $23 \mathrm{~mm}$ & $3.53(-1.68$ to 8.75$)$ & .18 & 0.042 (-6.91 to 7.00$)$ & .99 \\
\hline $23 \mathrm{~mm}$ vs $26 \mathrm{~mm}$ & $1.77(-2.21$ to 5.37$)$ & .38 & $-0.22(-6.09$ to 4.36$)$ & .93 \\
\hline
\end{tabular}

$B V F$, Bioprosthetic valve fracture; $V I V T A V R$, valve in valve transcatheter aortic valve replacement; $T H V$, transcatheter heart valve; $I D$, internal diameter. *Beta weight represents the effect of the specific factor on the final mean transvalvular gradient in millimeters mercury.

VIV TAVR and BVF resulted in complete resolution of the leak. BVF resulted in severe THV insufficiency in 2 cases. One case involved a Sapien S3 and 1 case involved a CoreValve Evolut R; the etiology of the acute THV damage could not be determined. In both cases, the THV insufficiency resolved with placement of a second THV. One patient developed new severe mitral insufficiency following BVF and underwent successful transcatheter mitral valve repair with Mitraclip (Abbott, Minneapolis, Minn). Two patients experienced cerebrovascular accidents (on postprocedure day 2 and 4, respectively); both recovered without residual deficit.

Table 2 summarizes characteristics and hemodynamic results based on timing of BVF. Final mean transvalvular gradient was significantly lower when compared with baseline $(9.2 \pm 6.3 \mathrm{~mm} \mathrm{Hg}$ vs $40.3 \pm 15.8 \mathrm{~mm} \mathrm{Hg}$; $P<.001)$ but was significantly lower in patients who underwent BVF after VIV TAVR compared with patients who had BVF first followed by VIV TAVR $(8.1 \pm 4.8 \mathrm{~mm} \mathrm{Hg}$ vs $16.9 \pm 10.1 \mathrm{~mm} \mathrm{Hg} ; P<.001)$. Final calculated valve EOA was significantly higher when compared with baseline $\left(2.1 \pm 0.8 \mathrm{~cm}^{2}\right.$ vs $0.8 \pm 0.3 \mathrm{~cm}^{2}$; $P<.001)$. Univariable and multivariable predictors of the final mean transvalvular gradient are summarized in Table 3. In the multivariable analysis, performing BVF after VIV TAVR $(P<.0001)$ and using a large BVF balloon $(P=.013)$ were the only independent predictors of lower final mean transvalvular gradient.

Because a strategy of performing BVF after VIV TAVR resulted in a lower final mean gradient, we performed additional analyses to explore the optimal technique for this approach (Figure 2). Patients who underwent BVF after
VIV TAVR had a baseline mean prosthetic valve gradient of $40.6 \pm 15.8 \mathrm{~mm} \mathrm{Hg}$ with a mean valve EOA of $0.8 \pm 0.3 \mathrm{~cm}^{2}$. Following VIV TAVR, the residual mean gradient (before BVF) was reduced to $19.0 \pm 8.8 \mathrm{~mm} \mathrm{Hg}$ $(P<.001)$ with an increase in the mean valve EOA to $1.4 \pm 0.8 \mathrm{~cm}^{2}(P<.001)$. Following BVF, the mean transvalvular gradient was further reduced to $8.1 \pm 4.8 \mathrm{~mm} \mathrm{Hg}(P<.001)$ and resulted in a further increase in valve $\mathrm{EOA}$ to $2.1 \pm 0.8 \mathrm{~cm}^{2}(P<.001)$. Univariable and multivariable predictors for final mean gradient among those patients who had BVF after VIV TAVR are summarized in Table 4; using a BVF balloon that was $\geq 3 \mathrm{~mm}$ larger than the surgical valve true ID being fractured demonstrated a strong trend toward a lower final transvalvular gradient $(P=.051)$ in this subgroup analysis.

\section{DISCUSSION}

In this multicenter, retrospective, observational study involving 21 centers, BVF in conjunction with VIV TAVR appeared to be generally safe and resulted in a significant reduction in residual gradients and an increase in valve EOA compared with VIV TAVR alone. In a hierarchical multiple linear regression analysis, after adjusting for other baseline patient and valve-related factors, the only procedural factors that were associated with a lower final mean gradient were performing BVF after VIV TAVR and performing $\mathrm{BVF}$ with a balloon that was at least $3 \mathrm{~mm}$ larger than the true ID of the surgical valve being fractured.

In the Valve-in-Valve International Data Registry, the incidence of severe PPM (defined as a mean gradient $\geq 20 \mathrm{~mm} \mathrm{Hg}$ following VIV TAVR) was 32\%. Moreover, 


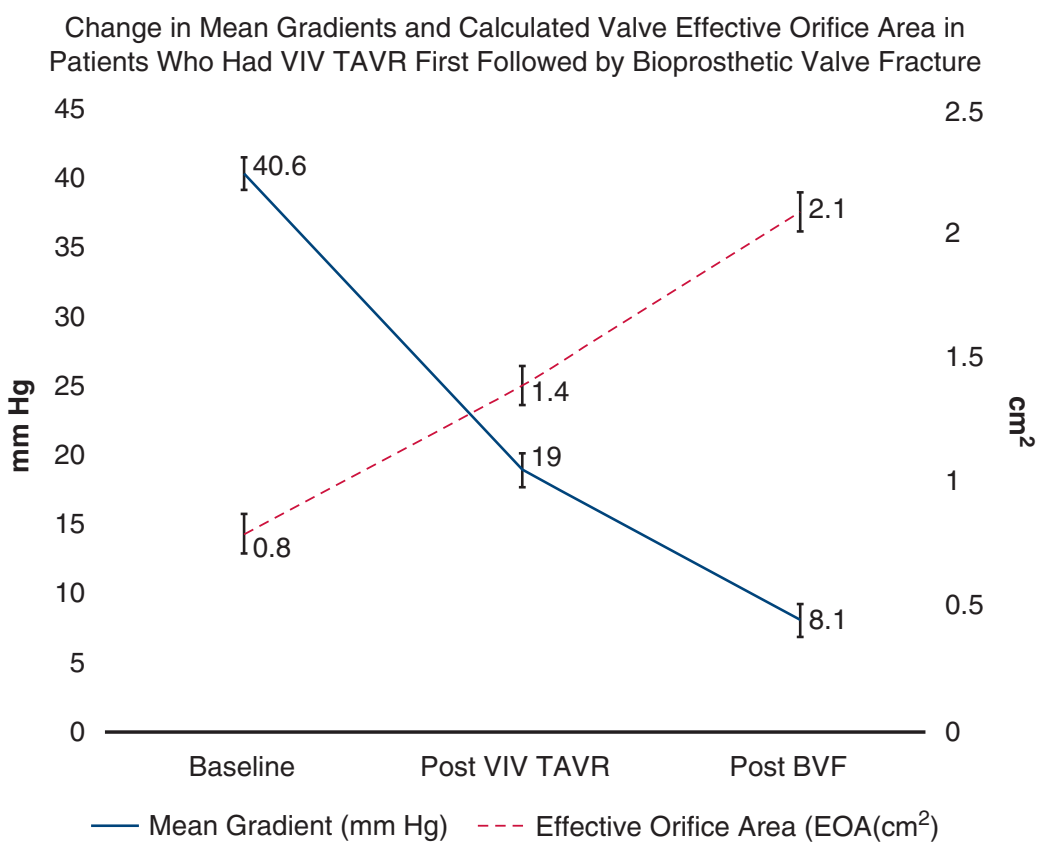

FIGURE 2. The influence of bioprosthetic valve fracture (BVF) on reducing high residual gradients following valve-in-valve transcatheter aortic valve replacement $(V I V T A V R)$ is demonstrated best in those patients who underwent BVF after VIV TAVR that allowed the patient to serve as his own control with hemodynamic values obtained at baseline, following VIV TAVR, and then following BVF. Baseline mean prosthetic valve gradient was $40.6 \pm 15.8 \mathrm{~mm} \mathrm{Hg}$ with a mean valve effective orifice area (EOA) of $0.8 \pm 0.3 \mathrm{~cm}^{2}$. Following VIV TAVR, although the mean gradient was reduced to $19.0 \pm 8.8 \mathrm{~mm} \mathrm{Hg}(P<.001)$ and the mean valve EOA was increased to $1.4 \pm 0.8 \mathrm{~cm}^{2}(P<.001)$, the residual mean gradient remained high and concerning for patient-prosthetic mismatch. Following BVF, the mean transvalvular gradient was further reduced to $8.1 \pm 4.8 \mathrm{~mm} \mathrm{Hg}(P<.001)$ and resulted in a further increase in valve EOA to $2.1 \pm 0.8 \mathrm{~cm}^{2}(P<.001)$ with resolution of concerns for patient-prosthetic mismatch.

there was a significant difference in 1-year mortality in patients with small $(\geq 21 \mathrm{~mm})$ and intermediate $(>21$ to $<25 \mathrm{~mm}$ ) sized surgical valves compared with large $(\geq 25 \mathrm{~mm})$ labeled surgical valves, respectively $(25 \%$ vs $18 \%$ vs $7 \% ; P=.001){ }^{6}$ More recently, Webb and colleagues ${ }^{8}$ reported significantly greater 1 -year mortality $(16.7 \%$ vs $7.7 \%)$ in patients with residual mean gradients $\geq 20 \mathrm{~mm} \mathrm{Hg}$ following VIV TAVR in the Placement of Aortic Transcatheter Valves Trial (PARTNER) 2 Valve-inValve Registry. Finally, Pibarot and colleagues ${ }^{10}$ demonstrated that pre-existing PPM in a failed surgical valve was a strong independent predicator of mortality following VIV TAVR. The safe application of BVF may change this paradigm by reducing residual gradients following VIV TAVR and may allow VIV TAVR to be performed more effectively in patients with small surgical valves or preexisting PPM who are not good candidates for reoperation. Whether BVF should be performed, regardless of the residual gradient or surgical valve size, to optimize THV expansion, prevent the constrained THV from pinwheeling, and potentially improve durability will require further investigation..$^{20,21}$

The timing of BVF in relation to VIV TAVR involves a balance between the potential for producing catastrophic surgical valve insufficiency versus the unknown influence of high-pressure balloon inflation on the acute structural integrity and long-term durability of the THV leaflets. Indeed, acute damage to the THV occurred in $3 \%$ of patients (2 out of 66) in this series who underwent BVF after VIV TAVR. However, performing BVF after VIV TAVR and using a noncompliant balloon that was at least $3 \mathrm{~mm}$ larger than the true ID of the surgical valve were independent predictors of achieving a lower final transvalvular gradient.

These findings correlate with previous bench testing, ${ }^{11}$ which suggested that BVF results in an increase in the ID of the surgical valve of 3 to $4 \mathrm{~mm}$ with labeled valve sizes of $19 \mathrm{~mm}$ and $21 \mathrm{~mm}$, respectively. ${ }^{11} \mathrm{BVF}$ performed before VIV TAVR may be effective at fracturing the surgical valve but does not ensure adequate expansion of the subsequently implanted THV. This is particularly true with the balloon expandable Sapien THV whose compliant delivery balloon does not generate sufficient pressure to fully expand the THV in a fractured surgical valve. ${ }^{11}$ Although bench testing demonstrated that the radial force exerted by the self-expanding CoreValve was adequate to expand a new, nondegenerated surgical valve that had been fractured, the results from this series suggest that in vivo, a degenerated surgical valve may impede even self-expanding THVs 
TABLE 4. Univariable and multivariable predictors of final mean gradient when bioprosthetic valve fracture (BFV) was performed after valve-invalve transcatheter aortic valve replacement (VIV TAVR) $(n=66)$

\begin{tabular}{|c|c|c|c|c|}
\hline \multirow[b]{2}{*}{ Variable } & \multicolumn{2}{|c|}{ Univariate association } & \multicolumn{2}{|c|}{ Multivariable association } \\
\hline & $\begin{array}{c}\text { Beta weight } * \\
(95 \% \text { confidence interval })\end{array}$ & $P$ value & $\begin{array}{c}\text { Beta weight* } \\
(95 \% \text { confidence interval })\end{array}$ & $P$ value \\
\hline Self-expandable THV type & $1.23(-1.20$ to 3.66$)$ & .31 & $1.57(-1.71$ to 4.84$)$ & .34 \\
\hline THV right sized vs up sized & $0.69(-1.84$ to 3.07$)$ & .549 & $1.93(-2.18$ to 4.84$)$ & .35 \\
\hline \multicolumn{5}{|l|}{ Surgical valve true ID } \\
\hline Small vs large & $4.53(-2.54$ to 11.60$)$ & .20 & $5.91(-3.86$ to 15.69$)$ & .23 \\
\hline Medium vs large & $4.96(-2.14$ to 12.07$)$ & .17 & $5.01(-3.47$ to 13.49$)$ & .23 \\
\hline Baseline mean gradient $(\mathrm{mm} \mathrm{Hg})$ & $0.06(-0.02$ to 0.13$)$ & .13 & $0.05(-0.04$ to 0.14$)$ & .24 \\
\hline \multicolumn{5}{|l|}{ Mode of valve failure } \\
\hline Insufficiency vs mixed & $-4.18(-8.67$ to 0.31$)$ & .068 & $-2.11(-7.40$ to 3.18$)$ & .42 \\
\hline Stenosis vs mixed & $-0.79(-4.63$ to 3.05$)$ & .68 & $-0.63(-5.09$ to 3.3 .84$)$ & .78 \\
\hline BVF balloon size minus surgical valve true ID $\geq 3 \mathrm{~mm}$ vs $<3 \mathrm{~mm}$ & $3.02(-0.62$ to 6.45$)$ & .084 & $3.30(-0.61$ to 7.22$)$ & .095 \\
\hline \multicolumn{5}{|l|}{ THV size } \\
\hline $20 \mathrm{~mm}$ vs $23 \mathrm{~mm}$ & $1.04(-3.45$ to 4.11$)$ & .64 & $-1.39(-8.02$ to 5.34$)$ & .67 \\
\hline $23 \mathrm{~mm}$ vs $26 \mathrm{~mm}$ & $0.90(-2.31$ to 4.11$)$ & .58 & $-1.51(-5.99$ to 2.98$)$ & .50 \\
\hline
\end{tabular}

$T H V$, Transcatheter heart valve; $I D$, internal diameter; $B V F$, bioprosthetic valve fracture. *Beta weight represents the effect of the specific factor on the final mean transvalvular gradient in millimeters mercury.

from fully expanding when using a BVF-first strategy. Therefore, to maximize the increase in diameter achieved with BVF, the THV itself needs to be dilated with a high-pressure balloon inflation, as occurs when BVF is performed after VIV TAVR.

Successful BVF has been consistently achieved using balloons $1 \mathrm{~mm}$ larger than the labeled valve size, which, for most surgical valves equates to a balloon 3 to $4 \mathrm{~mm}$ larger than the true ID. ${ }^{11-13}$ Although smaller balloons can fracture the surgical valve, their use was associated with higher final mean gradients $(P=.013)$ in this study. This finding suggests that the use of smaller balloons when performing BVF results in suboptimal THV expansion. As such, postdilation with a larger balloon and high-pressure inflation should be performed, particularly if performing BVF before VIV TAVR, to optimize the hemodynamic result.

Selection of THV implant size is not always straightforward when BVF is performed because the size of the selected THV should be based on the anticipated 3- to 4-mm increase in the true ID of the surgical valve with BVF. Indeed, a frequent question is whether to right size the THV, which can be optimally expanded following BVF, or whether to up size to a larger THV, which, although still

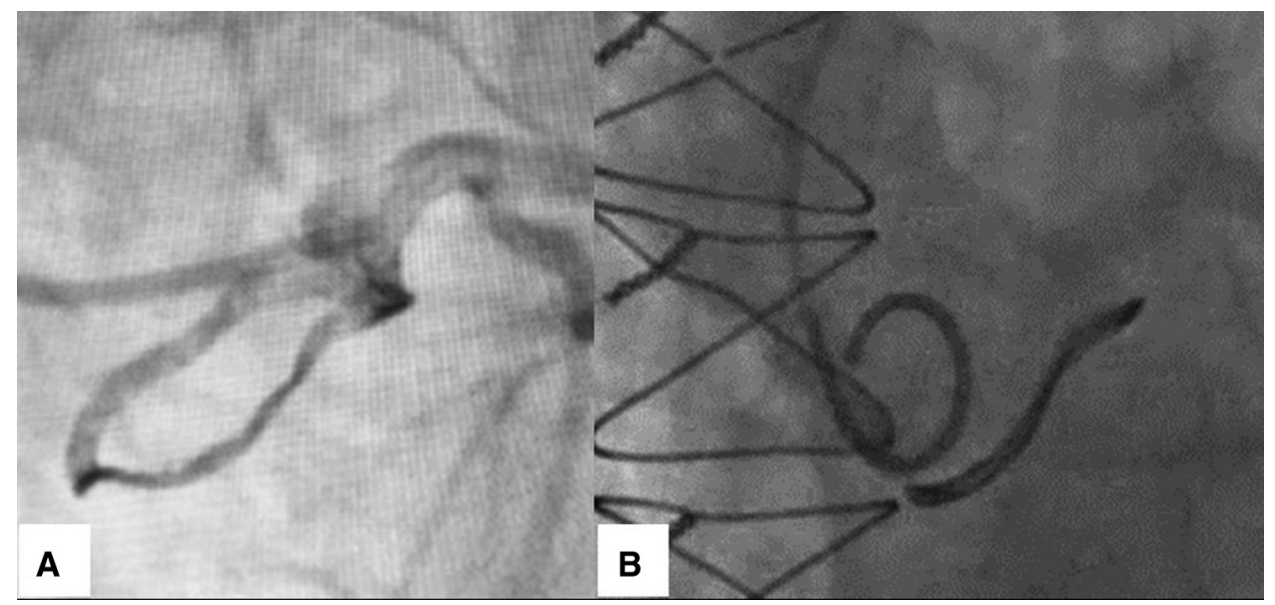

FIGURE 3. A, Potential contraindications to valve-in-valve transcatheter aortic valve replacement (VIV TAVR) and bioprosthetic valve fracture (BVF) are demonstrated in this coronary angiogram that demonstrates a very low left main in relation to a 19-mm Mitroflow (Livanova/Sorin, Milan, Italy) with (B) chimney root and no coronary sinuses into which the fractured valve can expand. This patient would be at high risk for coronary obstruction and potential injury to the aortic root. The patient underwent uneventful reoperation rather than VIV TAVR with BVF. 
constrained, may provide a larger EOA and superior hemodynamic parameters. In this study, up sizing the THV did not result in a lower final mean gradient or larger EOA following BVF. The ability to up size the THV with BVF may therefore be beneficial only when the surgical valve ID is so small that VIV TAVR is not recommended at all with currently available THV sizes.

Given the concern for PPM and increased mortality with VIV TAVR in small surgical valves, research has shown that optimizing implantation depth of both balloon expandable and self-expanding expanding THVs is critical for minimizing residual gradients. ${ }^{22-25}$ Simonato and colleagues ${ }^{24,25}$ demonstrated that high implants (depths $0-1 \mathrm{~mm}$ in relation to the valve frame) across a variety of THVs resulted in more favorable hemodynamic values. Although randomized trials comparing THV types have not been performed, observational studies suggest that the use of a supra annular rather than an intra-annular THV may also decrease the incidence of high residual gradients following VIV TAVR. ${ }^{6,7,10}$ In this study, THV type was not associated with a lower final mean gradient following BVF. These finding suggest that if there is any hemodynamic downside to using intra-annular THVs during VIV TAVR it may be overcome by performing BVF.

There are several limitations to this study. This was a retrospective, observational study. Although significant reductions in residual gradients following VIV TAVR can be safely obtained with BVF, the long-term influence of this approach on patient outcomes, the durability of the low gradients and whether BVF alters transcatheter valve durability (either positively or negatively) will require longer follow-up. Furthermore, BVF is not without complications. As previously described, proper patient selection, device selection, and procedural technique during BVF are essential to avoid complications. ${ }^{11-13}$ Whereas some procedurerelated complications might be mitigated by appropriate balloon sizing and positioning during BVF, operator awareness, particularly regarding the risk of coronary artery obstruction during VIV TAVR, regardless of whether BVF is performed, is paramount. Low coronary origins (Figure 3, A) or patients with chimney roots with narrow sinuses should be avoided (Figure 3,B). ${ }^{26}$ Although annular rupture was not observed in this series, avoiding BVF in heavily calcified roots and in patients with surgical valves implanted intra- rather than supra-annular may be important.

\section{CONCLUSIONS}

BVF can be performed safely to facilitate VIV TAVR with either balloon expandable or self-expanding THVs and results in reduced residual transvalvular gradients and increased valve EOA; however, BVF performed after VIV TAVR and using a noncompliant balloon at least $3 \mathrm{~mm}$ larger than the true ID of the surgical valve being fractured achieves the best hemodynamic results.

\section{Conflict of Interest Statement}

Drs Allen and Chhatriwalla have performed research/ clinical trial support/proctoring/speakers bureau duties for Abbott Vascular, Edwards Lifesciences, and Medtronic. Dr Cohen has performed research/clinical trial support for Medtronic, Abbott Vascular, Edwards Lifesciences, and Boston Scientific as well as consulting services for Medtronic and Edward Lifesciences. Dr Rovin has been a proctor/consultant for Medtronic and a proctor and speakers bureau member for Abbott. Dr Nguyen has performed research/clinical trial support/proctoring for Abbott Vascular, Edwards Lifesciences, and LivaNova. Dr Dvir has provided research/clinical trial support/consulting for Medtronic, Abbott Vascular, and Edwards Lifesciences. Dr Webb has been a consultant for Edwards Lifesciences and Abbott Vascular and has performed research/clinical trial support/proctoring/speakers bureau duties for Medtronic, Abbott Vascular, and Edwards Lifesciences. Dr Whisenant has provided consulting services for Boston Scientific and Edwards Lifesciences. Dr Bavry has received travel support from Edwards Lifesciences.

Dr Thourani has performed research/clinical trial services for Edwards Lifesciences and been on the Advisory Board of Edwards Lifesciences, Boston Scientific, Abbott Vascular, Gore Vascular, and Cryolife. Dr Loyalka has been a proctor for Abbott. All other authors have nothing to disclose with regard to commercial support.

Additional collaborators not listed as authors who encompass the Bioprosthetic Valve Fracture Investigators include Sanjeev Aggarwal, MD (Saint Luke's Mid America Heart Institute, Kansas City, Mo); Suzanne Baron, MD, MSc (Saint Luke's Mid America Heart Institute, Kansas City, Mo); Anthony Hart, MD, Saint Luke's Mid America Heart Institute, Kansas City, Mo); J. Russell Davis, MD (Saint Luke's Mid America Heart Institute, Kansas City, Mo); A. Michael Borkon, MD, Saint Luke's Mid America Heart Institute, Kansas City, Mo); Sathananthan Janarthanan, MD (University of British Columbia, Vancouver, BC, Canada); Thomas Beaver, MD (University of Florida, Gainesville, Fla); Ashkan Karimi, MD (University of Florida, Gainesville, Fla); Dennis Gory, MD, Peace Health Medical Group, Eugene, Ore); Lang Lin, MD (Morton Plant Hospital, Clearwater, Fla); Douglas Spriggs, MD (Morton Plant Hospital, Clearwater, Fla); John Ofenloch, MD (Morton Plant Hospital, Clearwater, Fla); Abhijeet Dhoble, MD (University of Texas Medical School at Houston, Houston, Tex); Brian Hummel, MD (Lee Memorial Hospital, Fort Myers, Fla); Mark Russo, MD (Newark Beth Israel Medical Center, Newark, NJ); Bruce Haik, MD (Newark Beth Israel Medical Center, Newark, NJ); Michael Lim, MD (Saint Louis University School of Medicine, Saint Louis, Mo); Vasilis Babaliaros, MD (Emory University, Atlanta, Ga); Adam Greenbaum, MD (Henry Ford Detroit Medical Center, Detroit, Mich); William O’Neill, MD (Henry Ford Detroit Medical Center, Detroit, Mich); Juhana Karha, MD (Austin Heart Clinic, Austin, Tex); D. W. Park, MD (Asan Medical Center, Seoul, South Korea); 
Ed Garrett, MD (Baptist Memorial Hospital, Memphis, Tenn); Alex Pak, MD (North Kansas City Hospital, North Kansas City, Mo); Zafir Hawa, MD (North Kansas City Hospital, North Kansas City, Mo); James Mitchell, MD (North Kansas City Hospital, North Kansas City, Mo); Axel Unbehaun, MD, PhD (Deutsches Herzzentrum Berlin, Berlin, Germany); Anwar Tandar, MD (University of Utah, Salt Lake City, Utah); Pradeep Yadav, MD (Hershey Medical Center, Hershey, Pa); Jason Ricci, MD (McLaren Northern Michigan Hospital, Petoskey, Mich); and Alan Yeung, MD (Stanford University, Stanford, Calif).

\section{References}

1. Smith CR, Leon MB, Mack MJ, Miller DC, Moses JW, Svensson LG, et al. Transcatheter versus surgical aortic-valve replacement in high-risk patients. N Engl J Med. 2011;364:2187-98.

2. Leon MB, Smith CR, Mack MJ, Makkar RR, Svensson LG, Kodali S, et al. Transcatheter or surgical aortic-valve replacement in intermediate-risk patients. $N$ Engl J Med. 2016;374:1609-20.

3. Adams DH, Popma JJ, Reardon MJ, et al. Transcatheter aortic-valve replacement with a self-expanding prosthesis. N Engl J Med. 2014;370:1790-8.

4. Leon MB, Smith CR, Mack M, Yakubov SJ, Coselli JS, Deeb GM, et al. Transcatheter aortic-valve implantation for aortic stenosis in patients who cannot undergo surgery. N Engl J Med. 2010;363:1597-607.

5. Leon MB, Smith CR. Transcatheter aortic-valve replacement. $N$ Engl J Med. 2016;375:700-1.

6. Dvir D, Webb J, Brecker S, Bleiziffer S, Hildick-Smith D, Colombo A, et al. Transcatheter aortic valve replacement for degenerative bioprosthetic surgical valves: results from the global valve-in-valve registry. Circulation. 2012;126: 2335-44.

7. Dvir D, Webb JG, Bleiziffer S, Pasic M, Waksman R, Kodoli S, et al. Transcatheter aortic valve implantation in failed bioprosthetic surgical valves. JAMA. 2014;312:162-70

8. Webb JG, Mack MJ, White JM, Dvir D, Blanke P, Herrman HC, et al. Transcatheter aortic valve implantation within degenerated aortic surgical bioprostheses: PARTNER 2 Valve-in-Valve Registry. J Am Coll Cardiol. 2017;69:2253-62.

9. Faerber G, Schleger S, Diab M, Breuer M, Figulla H, Eichinge W, et al. Valve-invalve transcatheter aortic valve implantation: the new playground for prosthesispatient mismatch. J Interv Cardiol. 2014;27:287-92.

10. Pibarot P, Sionato M, Barbanti M, Linke A, Kornowski R, Rudolph T, et al. Impact of pre-existing prosthesis-patient-mismatch on survival following aortic valve-in-valve procedures. J Am Coll Cardiol Intv. 2018;11:133-41.

11. Allen KA, Chhatriwalla AK, Cohen DJ, Saxon JT, Aggarwal S, Hart A, et al. Bioprosthetic valve fracture to facilitate transcatheter valve-in-valve implantation. Ann Thorac Surg. 2017;104:1501-8.

12. Chhatriwalla AK, Allen KB, Saxon JT, Baron S, Cohen DJ, Aggarwal S, et al. Bioprosthetic valve fracture improves the hemodynamic results of valve-invalve transcatheter aortic valve replacement. Circ Cardiovasc Interv. 2017;10.

13. Saxon JT, Allen KB, Cohen DJ, Chhatriwalla A. Bioprosthetic valve fracture (BVF) during VIV TAVR: bench to bedside. Interv Cardiol Rev. 2018;13:20-6.

14. Nielsen-Kudsk JE, Christiansen EH, Terkelsen CJ, Norgaard BL, Jensen KT, Krusell LR, et al. Fracturing the ring of small Mitroflow bioprostheses by high-pressure balloon predilatation in transcatheter aortic valve-in-valve implantation. Circ Cardiovasc Interv. 2015;8:e002667.

15. Brown SC, Cools B, Gewillig M. Cracking a tricuspid perimount bioprosthesis to optimize a second transcatheter sapien valve-in-valve placement. Catheter Cardiovasc Interv. 2016;88:456-9.

16. Tanase D, Grohmann J, Schubert S, Uhlemann F, Eicken A, Ewert P. Cracking the ring of Edwards Perimount bioprosthesis with ultrahigh pressure balloons prior to transcatheter valve in valve implantation. Int J Cardiol. 2014;176:1048-9.

17. Nielsen-Kudsk JE, Andersen A, Therkelsen CJ, Christensen EH, Jensen KT, Krusell LR, et al. High-pressure balloon fracturing of small dysfunctional Mitroflow bioprostheses facilitates transcatheter aortic valve-in-valve implantation. EuroIntervention. 2017;13:e1020-5.

18. Johansen P, Engholt H, Tang M, Nybo RF, Rasmussen PD, Nielsen-Kudsk JE. Fracturing mechanics before valve-in-valve therapy of small aortic bioprosthetic heart valves. EuroIntervention. 2017;13:e1026-31.

19. UBQO. Valve in valve (version 2.0) [Mobile application software]. London, United Kingdom; 2018. Retrieved from: http://itunes.apple.com.
20. Sathananthan J, Sellers S, Barlow A, Stanova V, Fraser R, Toggweiler S, et al Valve-in-valve transcatheter aortic valve replacement and bioprosthetic valve fracture comparing different transcatheter heart valve designs: an ex-vivo bench study. JACC Cardiovasc Interv. 2019;12:65-75.

21. Chhatriwalla A, Saxon J, Cohen DJ, Allen KB. Is bioprosthetic valve fracture beneficial in patients with larger surgical valves undergoing VIV TAVR. Curr Cardiol Rep. 2018;20:95-100.

22. Zenses AS, Mitchell J, Evin M, Stanova V, Obadia JF, Pibarot P, et al. In vitro study of valve-in-valve performance with the CoreValve self-expandable prosthesis implanted in different positions and sizes within the Trifecta surgical heart valve. Comput Methods Biomech Biomed Engin. 2015;18(Suppl 1):2086-7.

23. Azadani AN, Reardon M, Simonato M, Aldea G, Nickenig G, Kornowski R, et al Effect of transcatheter aortic valve size and position on valve-in-valve hemodynamics: an in vitro study. J Thorac Cardiovasc Surg. 2017;153:1303-15.

24. Simonato M, Azadani AN, Webb J, Leipsic J, Kornowski R, Vahanian A, et al In vitro evaluation of implantation depth in valve-in-valve using different transcatheter heart valves. EuroIntervention. 2016;12:909-17.

25. Simonato M, Webb J, Kornowski R, Vahanian A, Frerker C, Nissen H, et al Transcatheter replacement of failed bioprosthetic valves: large multicenter assessment of the effect of implantation depth on hemodynamics after aortic valve-in-valve. Circ Cardiovasc Interv. 2016;9.

26. Dvir D, Leipsic J, Blanke P, Ribeiro HB, Kornowski R, Pichard A, et al. Coronary obstruction in transcatheter aortic valve-in-valve implantation: preprocedural evaluation, device selection, protection, and treatment. Circ Cardiovasc Interv. $2015 ; 8$.

Key Words: bioprosthetic valve fracture (BVF), valve in valve transcatheter aortic valve replacement (VIV TAVR)

\section{Discussion}

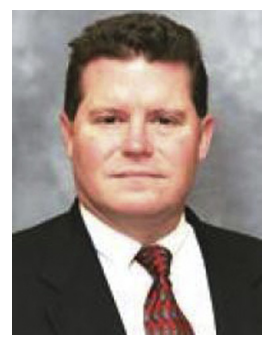

Dr Keith B. Allen (Kansas City, Mo). I appreciate the Western's invitation to present our data and on behalf of all of our investigators we want to thank you for this opportunity.

These are my disclosures. The abstract that I'm going to share with you has changed quite a bit from what will be published. We have learned a tremendous amount just in the past 6 months since the abstract was submitted and that's what I'm going to share with you.

Valve-in-valve transcatheter aortic valve replacement (TAVR) is an alternative to redo surgery and it is currently Food and Drug Administration approved for high-risk patients with failing tissue valves. However, valve-in-valve TAVR has problems, lots of problems, and this is particularly the case in patients with small surgical valves or preexisting prosthesis-patient mismatch where valve-invalve TAVR can result in high residual gradients, which are associated with worst outcomes, specifically increased mortality. Dvir and colleagues, ${ }^{7}$ using the VIVID registry, the Valve-in-Valve International Data Registry, looked at 1-year mortality after valve-in-valve TAVR. The data really does not look very good, and it's particularly poor in smaller surgical valves. The 1-year mortality in labeled surgical valves less than or equal to $21 \mathrm{~mm}$ was $25 \%$. Webb and colleagues ${ }^{8}$ looked at the impact of high residual gradients following valve-in-valve TAVR on 1-year mortality using the the the Placement of Aortic Transcatheter Valves 
(PARTNER) trial valve-in-valve registry. They defined a high residual gradient as greater than $20 \mathrm{~mm} \mathrm{Hg}$, which was clearly associated with an increased mortality. What I'm about to share with you is some might consider off-label, so listen and enter at your own risk.

We published about 2 years ago bench testing that demonstrated that bioprosthetic valve fracture, or BVF, when performed with a noncompliant balloon and a high-pressure inflation, can fracture some but not all surgical valves and allow further expansion of the transcatheter heart valve. We subsequently then looked at an 11-center clinical experience and demonstrated that $\mathrm{BVF}$ resulted in reduced residual gradients and increased valve effective orifice area following valve-in-valve TAVR. The following video demonstrates bench testing of a Sorin 21-mm Mitroflow being fractured. The audio demonstrates the audible snap of the valve being fractured as the cardiologist is counting atmospheres of pressure toward fracture. Sometimes you'll actually hear the snap coming from the patient. The objective of this trial was to provide insights from a larger, multicenter study and explore factors that might impact BVF outcomes that we were all questioning such as the timing of BVF, should you do it before or after valve-in-valve TAVR, optimal balloon size and does it make any difference whether you pick a self-expanding or a balloon expandable valve and does size matter? This was a retrospective observational study involving 21 centers. Left to the discretion of the local heart team was essentially everything. Timing of BVF before or after valve-in-valve TAVR, which valve to use, the size, the depth of implant and postoperative anticoagulation. None of that was prespecified. We did, though, categorize valves by their true internal diameter rather than their labeled valve size as either small, intermediate, or large. We also categorized the transcatheter heart valves as either being rightsized or up-sized based on whether the heart team selected a transcatheter valve size equal to, that would be rightsized, or larger than, that would be upsized, recommended by the valve and valve app for that particular valve. And finally, we looked at noncompliant balloons used to perform the fracture and categorized them as being small if they were less than $3 \mathrm{~mm}$ larger than the true internal diameter of the valve being fractured or large if they were $3 \mathrm{~mm}$ or larger than the true internal diameter of the valve being fractured.

Intraoperatively, invasive hemodynamic measurements and calculation of valve effective orifice area were performed at baseline, following implantation of the transcatheter valve, and then obviously after BVF. In patients who underwent BVF first, obviously we wouldn't have an after valve-in-valve TAVR gradient and so only baseline and final gradients were obtained.

This is what BVF looks like in a patient. Once again, counting the atmospheres toward fracture with fracture occurring at 18 atmospheres.
So that's what a Magna (Edwards Lifesciences, Irvine, Calif) looks like when it fractures and, characteristically, you'll often see the waist of the balloon disappear as the balloon fractures the surgical valve. The most characteristic signal that you fractured the valve is that you've got an acute drop in the indelfator pressure. BVF was performed successfully in 75 patients at 21 centers from March 2016 until April 2018 and that's what I'm going to report to you today.

A variety of surgical valves were fractured, but for the vast majority, they were either small or intermediate in size. Very few large valves were fractured. Baseline age was 74 , average STS predicted risk of mortality was $6.5 \%$, and most cases were done transfemorally; however, cases were also done using transcarotid, transcaval, and subclavian access.

Fifty-seven percent of the valves implanted were balloon expandable whereas $43 \%$ were were self-expanding.

The heart team, because they anticipated an increase in diameter following fracture, upsized the transcatheter valve in 53\% of cases and once again, by upsizing, if you were doing valve-in-valve on a 23-mm Magna, the valve-in-valve app would say you should use a 23-mm Sapien or a 23-mm CoreValve (Medtronic, Minneapolis, Minn). If you picked $23 \mathrm{~mm}$, you right sized. If you went to $26 \mathrm{~mm}$, that would be considered upsized. Large balloons, once again defined as $\geq 3 \mathrm{~mm}$ larger than the surgical valve being fractured, were used in $84 \%$ of patients. You might ask, how do we come up with the 3 ? Well, we know from bench testing that you get a 3- to 4-mm increase in diameter with labeled valves of $19 \mathrm{~mm}$ and $21 \mathrm{~mm}$, so that's where we got the $3 \mathrm{~mm}$.

Fracture thresholds range from 8 to 27 atmospheres. This video demonstrates a Magna Ease being fractured and clearly fracture thresholds vary with valve brand and valve size.

So the timing of BVF, whether before or after valve-invalve TAVR, is a hotly discussed topic in my small world of people doing BVF. BVF in this series was performed before valve-in-valve TAVR in $12 \%$ and it was performed after valve-in-valve TAVR in 88\%. In-hospital and/or 30-day mortality was 2.7\%: 2 deaths. Obviously, there are going to be complications, but to date, no coronary occlusions, no annular ruptures, either clinical or subclinical, no new pacemakers, $95 \%$ of patients had no aortic insufficiency, and in fact, 3 patients who had moderate perivalvular leaks after you expanded the valve had their perivalvular leak go away. There were 2 minor strokes, both recovered, no residuals. We did have early in our experience 1 mitral chordal tear that resulted in moderate to severe mitral regurgitation, subsequently successfully treated with a MitraClip (Abbott, Minneapolis, Minn), and we had 2 severe aortic insufficiencies from disruption of the TAVR valve, both treated successful with a second valve-in-valve.

Well, let's look at the hemodynamics of all the patients who were treated. Baseline was 40 , final gradient, after valve-in-valve TAVR and BVF, was reduced to 9.2. But when we analyzed the timing of BVF and its influence on 
gradients, if you performed BVF after valve-in-valve TAVR, your gradient was 8 . In those patients who underwent BVF first, it remained significantly higher at almost 17 .

So we looked at univariant predictors for best final hemodynamic parameters, including the transcatheter heart valve type, did you right or upsize the valve, what was the true internal diameter, mean baseline gradient, how did the surgical valve fail, stenosis or insufficiency or mixed, and what size balloon did you use and the timing of BVF. There were only 2 that were univariant predictors, using a larger balloon and performing BVF after valve-in-valve TAVR. We did a multivariable model with forced entry of all of these variables and once again, only large balloons and performing BVF after the valve-in-valve was done were significant predictors for best final gradient.

Because we knew that doing BVF after valve-in-valve was, for us, best practice, we analyzed those 66 patients that had BVF done after valve-in-valve TAVR, which allows us to use the patient as his own control. In these patients, baseline gradient was 41 , after valve-in-valve TAVR you get a significant reduction, but it's consistent with the valve-in-valve International Data Registry data and you get a high residual gradient of 19. Look what happens after you do BVF: Gradient now is single digits at 8 . You can flip this and now instead of gradient look at EOA: Baseline effective orifice area of the failed surgical valve was 0.8. You got a good bump when you did valve-in-valve. It went to 1.4 but look at it after you do BVF and it is 2. Remember, it doesn't take a lot of increase in radius or diameter of a circle to increase its area significantly. There clearly are limitations with this retrospective observational study and the long-term influence of BVF on clinical outcomes, the durability of the results, and whether BVF alters transcatheter heart valve durability either positive or negatively is going to require a lot more thoughtful study and longer follow-up.

So in conclusion, BVF can be performed safely and results in reduced residual gradients and increased valve area, best hemodynamic results are achieved by performing BVF after valve-in-valve TAVR and using a noncompliant balloon at least $3 \mathrm{~mm}$ larger than the true internal diameter of the surgical valve being fractured.

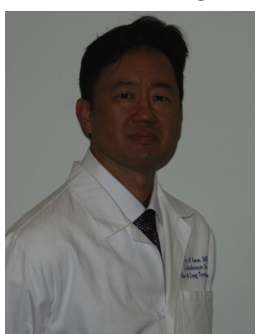

Dr Murray Kwon (Los Angeles, Calif). So I want to thank the Association for the opportunity to review this very well written report and for the authors for providing it early. It was very well written and I thought your results were very salient in this era of aortic valve treatment and your conclusions were appropriate. So I have a few questions, none of which I think you'll find too unpleasant. You mentioned the 4 patients who had perivalvular leaks in their existing surgical valves and I might have said well, unless they're prohibitive risks, these would be better handled in an open fashion. Do you think you might be heralding in a new indication for valve-in-valve TAVR that should say a bioprosthetic valve that's functioning okay, but with perivalvular leak that's leading to complications and that this may be a modality of treatment?

Dr Allen. This is a very provocative question and honestly, I don't know that you can answer it at this stage. But certainly, if a surgical valve has failed and it also has a perivalvular leak, the phone calls I get and recommendations I make are you don't do a perivalvular leak procedure, you don't plug it, you perform BVF, push it out, and most of the time that fixes the perivalvular leak. You can come back later if you still have residual.

Dr Kwon. Okay. The 2 cases you described where you had injury to the valve-in-valve TAVR, so now you're talking valve-in-valve-in-valve, can you comment on the specific hemodynamics of those 2 cases at the completion of those?

Dr Allen. One of them was a S3-not our center-and we don't have a good explanation after reviewing the case why it occurred. The second case was clearly on me and I take full responsibility for it, because during that time, I wanted to rightsize balloons with CoreValves. For those of you who do TAVR, you understand that there's a constrained area on the CoreValve, so a 23-mm CoreValve has an inflow of 23 but it bottlenecks to a constrained area of 20 and that's where the leaflets are attached. When you're doing BVF with CoreValves, you have to use a balloon that's no larger than 2-mm bigger than the constrained area. I wanted to use a 3-mm larger balloon and I tore one of the leaflets, so that was an avoidable error and something that we've learned and now teach.

Dr Kwon. I think as your experience grows, it might be helpful to parse out that separate population to see if there are higher gradients and lower effective orifice areas after that, getting to that. So you had lower gradients and effective orifice areas after your procedure, particularly in the after-TAVR BVF patients. As part of the Transcatheter Valve Therapy (TVT) Registry, you have 1-year echoes and since your study began in 2016, I'm wondering, do you have any early indication that there's different durability of these valves giving them very high-pressure insufflations at the time of their deployment?

Dr Allen. The conundrum of whether to BVF before or after VIV TAVR is balancing the risk of severe aortic insufficiency against the potential to damage the transcatheter heart valve with a high-pressure inflation. Industry is beginning to pay attention to this procedure but further support is clearly needed from industry to evaluate BVF.

Dr Kwon. Finally, I would like to just get your philosophy on the last question and then I'll sit down. But before I do, I just wanted to again congratulate you on a very well-written, thought-provoking contribution to our 
literature. Let's say you have a patient, a younger patient who you're trying to shepherd through life with a surgically implanted valve followed by 1 or 2 TAVRs in their lifetime. Does this change your philosophy in terms of prophylactic root enlargement procedures at the index first operation?

Dr Allen. What you're talking about is the emerging philosophy of life management of your aortic stenosis and I don't think we figured that out. Some people might argue that you'd be better off to get a TAVR first. When it fails, get a surgical procedure. When it fails, get a valve-in-valve with or without a BVF. So there's a lot of ways that you can argue it. The key is, as surgeons, the most common valve we implant is 21 , you need to put big valves in, and you have to realize that the internal diameter of different surgical valves are very different from their labeled valve size. You need to pay attention to the true internal diameter of the valves you're putting in and then whether or not the valve can be fractured down the road will begin to play a part in a surgeon's decision-making process, at least I think.

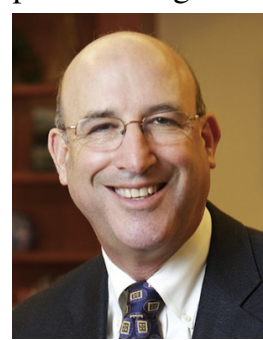

Dr Robbin Cohen (Los Angeles, Calif). Really great work and interesting and especially the in vitro stuff that you and others have done because I think that this is a situation where we're really actually learning about valves from some of the in vitro stuff, and my question is regarding pinwheeling-basically leaflet deformation that you get by putting too small a valve inside another valve, and you get pinwheeling of the leaflets or triangularization, 2 things that we really haven't seen in surgical valves, although we know that if you distort the sewing ring of a surgical valve to anything but round, it leads to early failure. So my question is, are you following these patients up with transthoracic echocardiography? Are you seeing the pinwheeling, the triangularization, and is it leading to early failure?

Dr Allen. So the beauty of doing BVF is that optimally expands the valve to a circular structure so for example, a 21-mm Magna that has a true internal diameter of $19 \mathrm{~mm}$, you break it, that true internal diameter now becomes 23 $\mathrm{mm}$, you can put a 23-mm CoreValve or a 23-mm Sapien in and that valve is perfectly and optimally expanded just the way the manufacturer meant it to be. There is no pinwheeling. Contrary, and the reason durability might play a role and why you might want to fracture every surgical valve, is to prevent just what you described. By definition, when you put a valve-in-valve inside, or transcatheter valve inside a surgical valve, it is constrained. It will pinwheel and it may actually fail prematurely, just like the surgical valve that's bent when you put it in. A really good observation.

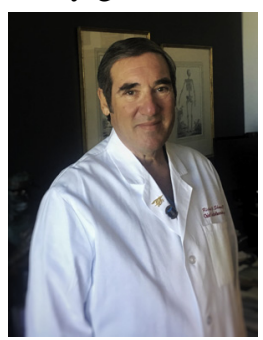

Dr Richard Shemin (Los Angeles, Calif). It seems that when you ramp up the atmospheres, it actually takes some time to do that and is there any hemodynamic instability that you're essentially creating? I assume you are rapidly pacing these individuals during this period of time, but it's usually longer than when we deploy a valve. Has that been a problem?

Dr Allen. It's a great question. The videos I showed you are older videos when we were very intrigued and went up slowly counting atmospheres toward fracture. Now we go up much faster because we know from our bench testing when a particular valve will fracture. Our pacing runs realistically are a tad bit longer, but not of any consequence. 
TABLE E1. Distribution of cases categorized by surgical valve model, labeled valve size, and the type and size of transcatheter heart valve implanted

\begin{tabular}{|c|c|c|c|c|c|c|c|c|}
\hline \multirow[b]{3}{*}{ Surgical valve brand* } & \multirow{3}{*}{$\begin{array}{c}\text { Labeled surgical } \\
\text { valve size }(\mathbf{m m})\end{array}$} & \multirow[b]{3}{*}{ Number treated } & \multicolumn{6}{|c|}{ Transcatheter valve implanted (mm) } \\
\hline & & & \multicolumn{3}{|c|}{$\begin{array}{l}\text { Self-expanding } \\
\quad(\mathbf{n}=\mathbf{3 2})\end{array}$} & \multicolumn{3}{|c|}{$\begin{array}{l}\text { Balloon expandable } \\
\qquad(\mathrm{n}=\mathbf{4 3})\end{array}$} \\
\hline & & & 23 & 26 & 29 & 20 & 23 & 26 \\
\hline \multirow[t]{5}{*}{ Magna } & 19 & 7 & 4 & 0 & 0 & 2 & 1 & 0 \\
\hline & 21 & 10 & 2 & 1 & 0 & 1 & 5 & 0 \\
\hline & 23 & 7 & 0 & 3 & 0 & 0 & 4 & 0 \\
\hline & 25 & 1 & 0 & 0 & 0 & 0 & 0 & 1 \\
\hline & 27 & 1 & 0 & 0 & 1 & 0 & 0 & 0 \\
\hline \multirow[t]{3}{*}{ Perimount 2800} & 19 & 4 & 4 & 0 & 0 & 0 & 0 & 0 \\
\hline & 21 & 4 & 1 & 0 & 0 & 0 & 3 & 0 \\
\hline & 23 & 4 & 1 & 2 & 0 & 0 & 1 & 1 \\
\hline \multirow[t]{2}{*}{ Magna Ease } & 19 & 1 & 0 & 0 & 0 & 1 & 0 & 0 \\
\hline & 23 & 1 & 0 & 0 & 0 & 0 & 1 & 0 \\
\hline \multirow[t]{3}{*}{ Mitroflow } & 19 & 4 & 0 & 0 & 0 & 4 & 0 & 0 \\
\hline & 21 & 7 & 4 & 0 & 0 & 1 & 3 & 0 \\
\hline & 25 & 1 & 0 & 0 & 0 & 0 & 0 & 1 \\
\hline \multirow[t]{4}{*}{ Mosaic } & 19 & 1 & 0 & 0 & 0 & 1 & 0 & 0 \\
\hline & 21 & 6 & 4 & 2 & 0 & 1 & 1 & 0 \\
\hline & 23 & 4 & 0 & 2 & 0 & 0 & 2 & 0 \\
\hline & 25 & 3 & 0 & 1 & 0 & 0 & 2 & 0 \\
\hline \multirow[t]{3}{*}{ Epic } & 21 & 4 & 2 & 0 & 0 & 0 & 2 & 0 \\
\hline & 23 & 3 & 0 & 0 & 0 & 0 & 3 & 0 \\
\hline & 27 & 1 & 0 & 0 & 0 & 0 & 0 & 1 \\
\hline Epic Supra & 19 & 1 & 0 & 0 & 0 & 1 & 0 & 0 \\
\hline
\end{tabular}

*Manufacturers of valve brands: Edwards Lifesciences, Irvine, Calif (Magna, Perimount 2800, Magna Ease); Livanova/Sorin, Milan, Italy (Mitroflow); Medtronic, Minneapolis, Minn (Mosaic); and St Jude Medical, St Paul, Minn (Epic, Epic Supra). 